\title{
Lithium and boron analysis by LA-ICP-MS results from a bowed PWR rod with contact
}

\author{
Anders Puranen ${ }^{1, *}$, Pia Tejland ${ }^{1}$, Michael Granfors ${ }^{1}$, David Schrire ${ }^{2}$, Bertil Josefsson ${ }^{2}$, and Bernt Bengtsson ${ }^{3}$ \\ 1 Studsvik Nuclear AB, 61182 Nyköping, Sweden \\ ${ }^{2}$ Vattenfall Nuclear Fuel AB, 16992 Stockholm, Sweden \\ 3 Ringhals AB, 43022 Väröbacka, Sweden
}

Received: 9 October 2015 / Accepted: 7 December 2016

\begin{abstract}
A previously published investigation of an irradiated fuel rod from the Ringhals 2 PWR, which was bowed to contact with an adjacent rod, identified a significant but highly localised thinning of the clad wall and increased corrosion. Rod fretting was deemed unlikely due to the adhering oxide covering the surfaces. Local overheating in itself was also deemed insufficient to account for the accelerated corrosion. Instead, an enhanced concentration of lithium due to conditions of local boiling was hypothesised to explain the accelerated corrosion. Studsvik has developed a hot cell coupled LA-ICP-MS (Laser Ablation Inductively Coupled Plasma Mass Spectrometer) equipment that enables a flexible means of isotopic analysis of irradiated fuel and other highly active surfaces. In this work, the equipment was used to investigate the distribution of lithium $\left({ }^{7} \mathrm{Li}\right)$ and boron $\left({ }^{11} \mathrm{~B}\right)$ in the outer oxide at the bow contact area. Depth profiling in the clad oxide at the opposite side of the rod to the point of contact, which is considered to have experienced normal operating conditions and which has a typical oxide thickness, evidenced levels of $\sim 10-20 \mathrm{ppm}{ }^{7} \mathrm{Li}$ and $\mathrm{a}^{11} \mathrm{~B}$ content reaching hundreds of ppm in the outer parts of the oxide, largely in agreement with the expected range of $\mathrm{Li}$ and $\mathrm{B}$ clad oxide concentrations from previous studies. In the contact area, the ${ }^{11} \mathrm{~B}$ content was similar to the reference condition at the opposite side. The ${ }^{7} \mathrm{Li}$ content in the outermost oxide closest to the contact was, however, found to be strongly elevated, reaching several hundred ppm. The considerable and highly localised increase in lithium content at the area of enhanced corrosion thus offers strong evidence for a case of lithium induced breakaway corrosion during power operation, when rod-to-rod contact and high enough surface heat flux results in a very local increase in lithium concentration.
\end{abstract}

\section{Introduction}

\subsection{Background}

Results presented at the 2014 WRFPM [1] concerned a bowed fuel rod with rod-to-rod contact from the Ringhals 2 PWR in Sweden. The contact was identified in the peripheral row of an assembly during routine inspection at end of cycle unloading. Because poolside camera inspection indicated possible increased local corrosion at the contact area, it was decided to transport the rod to Studsvik for hot cell post-irradiation examinations (PIE).

The previously presented PIE [1] identified a significant but highly localised thinning of the clad wall and increased corrosion at the contact area. Rod fretting was deemed unlikely due to the adhering oxide covering the surfaces. Local overheating in itself was also deemed insufficient to account for the accelerated corrosion. The increased clad oxidation

\footnotetext{
* e-mail: anders.puranen@studsvik.se
}

rate was, however, explainable by proposed $\mathrm{Li}$ induced corrosion enhancement under local boiling [2,3]. Enhanced concentrations of $\mathrm{Li}$ and $\mathrm{B}$ due to conditions of local boiling in the crevice-like rod-to-rod contact area was thus hypothesised to explain the accelerated corrosion. The potential role of B might, however, also be of a beneficial nature [4].

In this work, additional examinations to investigate the distribution of lithium $\left({ }^{7} \mathrm{Li}\right)$ and boron $\left({ }^{11} \mathrm{~B}\right)$ in the outer oxide at the bow contact elevation are presented.

\subsection{Fuel and operating history data}

Key fuel and operating data are summarised below. Additional data can be found in [1].

- Rod position D15, $15 \times 15$, AFA-3G assembly design, $\mathrm{M} 5^{\mathrm{TM}}$ cladding.

- Rod average burnup $53.1 \mathrm{MWd} / \mathrm{kgU}$, accumulated over four $\sim 12$ month cycles.

- Axial elevation of contact $\sim 1142 \mathrm{~mm}$, in the relatively long 2nd to 3rd spacer span. 
- The contact occurred during the last cycle, as evidenced by video from the previous end of the cycle inspection.

- Last cycle linear heat rate at contact elevation decreasing from $\sim 19$ to $13 \mathrm{~kW} / \mathrm{m}$ during the cycle. No boiling is expected at this elevation during normal operation.

- Last cycle reactor ${ }^{7} \mathrm{Li}$ concentration $5 \mathrm{ppm}$, decreasing to $\sim 2$ ppm.

\subsection{Previous PIE results}

Key findings from the previous PIE[1] of the rod are summarised below.

- Peak Eddy Current (EC) oxide thickness at contact area $\sim 35-50 \mu \mathrm{m}$, average oxide thickness away from contact area $\sim 8-10 \mu \mathrm{m}$.

- Contact region clad thinning up to $100 \mu \mathrm{m}$ (transverse optical microscopy).

- Lost clad thickness corresponds to $\sim 170 \mu \mathrm{m}$ of oxide (assuming a Pilling-Bedworth ratio of 1.55). Significant oxide spalling probably occurred.

- Reduced clad Vickers hardness in contact region, $\sim 215 \mathrm{HV}$ compared to $\sim 232 \mathrm{HV}$.

- Peak outer oxide temperature at contact $\sim 360^{\circ} \mathrm{C}$ (calculated from HV and LHR).

Figure 1 shows an overview of the contact region at $0^{\circ}$ at $1142 \mathrm{~mm}$ elevation (from previous PIE of the rod). Figure 2 shows views of the outer oxide at $0^{\circ}, 90^{\circ}, 180^{\circ}$ and $270^{\circ}$.

\section{Additional post-irradiation examinations}

\subsection{Scope}

The scope of investigation consisted of cutting of the sample, $10 \mathrm{~mm}$ long near the rod-to-rod contact point followed by LA-ICP-MS (Laser Ablation Inductively Coupled Plasma Mass Spectrometry) investigation of the ${ }^{7} \mathrm{Li}$ and ${ }^{11} \mathrm{~B}$ content in the outer oxide.

\subsection{LA-ICP-MS method}

The LA-ICP-MS technique consists of a pulsed laser that ablates the material to be studied. A carrier gas transports the created aerosol for analysis to an Inductively Coupled Plasma Mass Spectrometer (ICP-MS).

The ablation equipment is a New-Wave UP-213 Nd:YAG laser mounted on a motorized $\mathrm{X}-\mathrm{Y}-\mathrm{Z}$ stage, in connection to an ablation chamber that is housed in a hot cell. The transport gas from the ablation cell is injected into a Perkin-Elmer Elan 6100 DRC II ICP-MS, coupled to a glove box. The laser operates at a wavelength of $213 \mathrm{~nm}$ with a pulse length of $<4 \mathrm{~ns}$. The ablated spot size can be varied between $\sim 5$ and $160 \mu \mathrm{m}$ with an ablation frequency of $1-20 \mathrm{~Hz}$. The equipment can be used for spot analysis (drilling) or for line scans (typical traversing speed 10-140 $\mu \mathrm{m} / \mathrm{s}$ ).

For the results presented in this paper, a laser spot size of either $160 \mu \mathrm{m}$ diameter (example in Fig. 3) or a square $95 \mu \mathrm{m}$ line scanning beam was used (example in Fig. 4). An ablation frequency of $5 \mathrm{~Hz}$ and $100 \%$ intensity was employed. The carrier gas through the ablation chamber was He $(\sim 800 \mathrm{ml} / \mathrm{min})$. A makeup flow of $\sim 700 \mathrm{ml} / \mathrm{min}$ of Ar was added to the carrier gas prior to the ICP-MS. The ICP-MS was optimised for the low mass range.

The laser is of the flat beam type as can be seen in Figures 3 and 4, which are examples from ablation on inactive autoclave oxidised claddings during the calibration of the instrument. Figure 3 shows example SEM images of the ablated craters after laser ablation on zirconium oxide for 1, 3, 6 and 12 seconds ( $5 \mathrm{~Hz}, 160 \mu \mathrm{m}$ spot).

Figure 4 shows a SEM image of the ablated track after multiple passages with a square beam (95 $\mu \mathrm{m}$ side) traversing between two pre-ablated spots, creating a rectangular track.

An ablation depth rate of $\sim 0.5 \mu \mathrm{m} / \mathrm{s}$ was achieved for the spot-wise analysis, alternatively a lateral depth resolution of $\sim 300 \mathrm{~nm}$ per passage was obtained when the beam was traversing the surface.

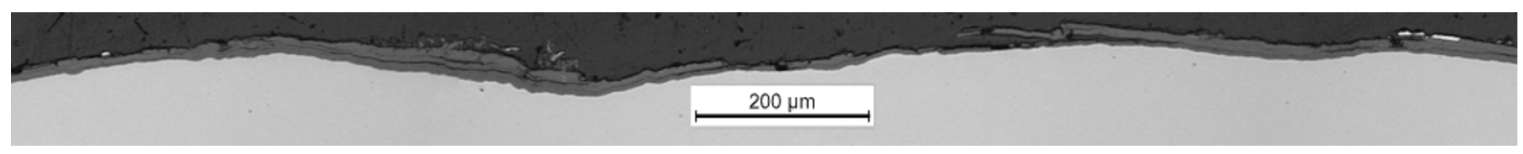

Fig. 1. Metallography overview of the contact region near $0^{\circ}(1142 \mathrm{~mm}$ elevation).

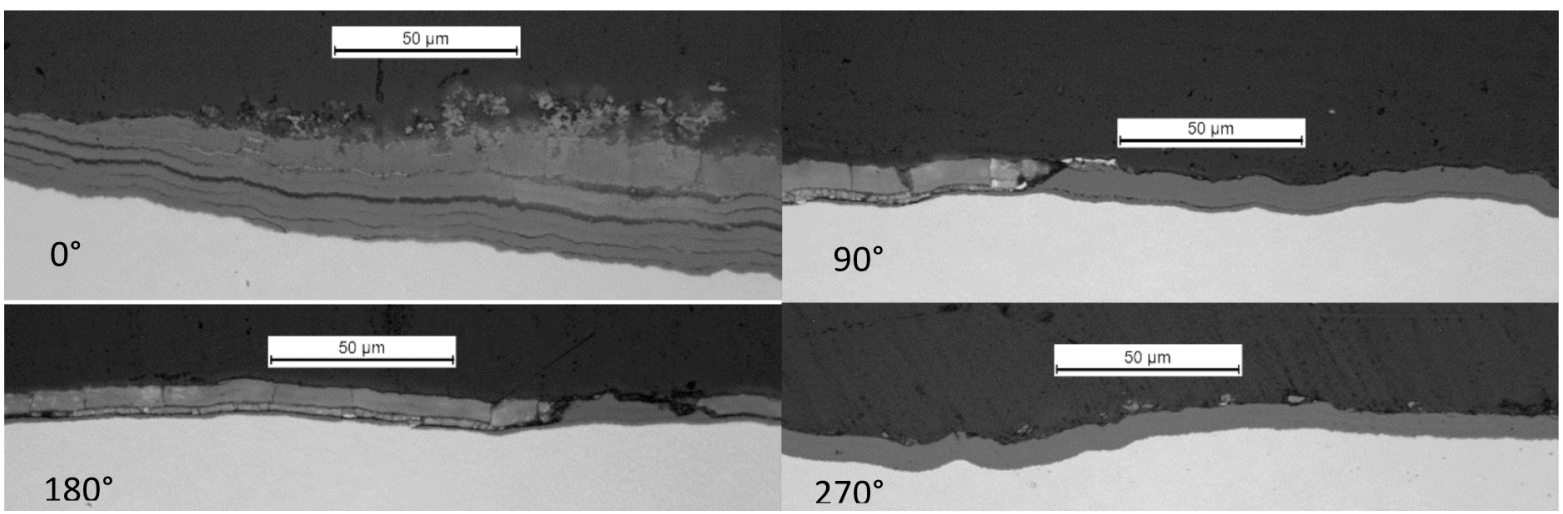

Fig. 2. Detailed metallography views of the outer oxide at $0^{\circ}, 90^{\circ}, 180^{\circ}$ and $270^{\circ}$. 


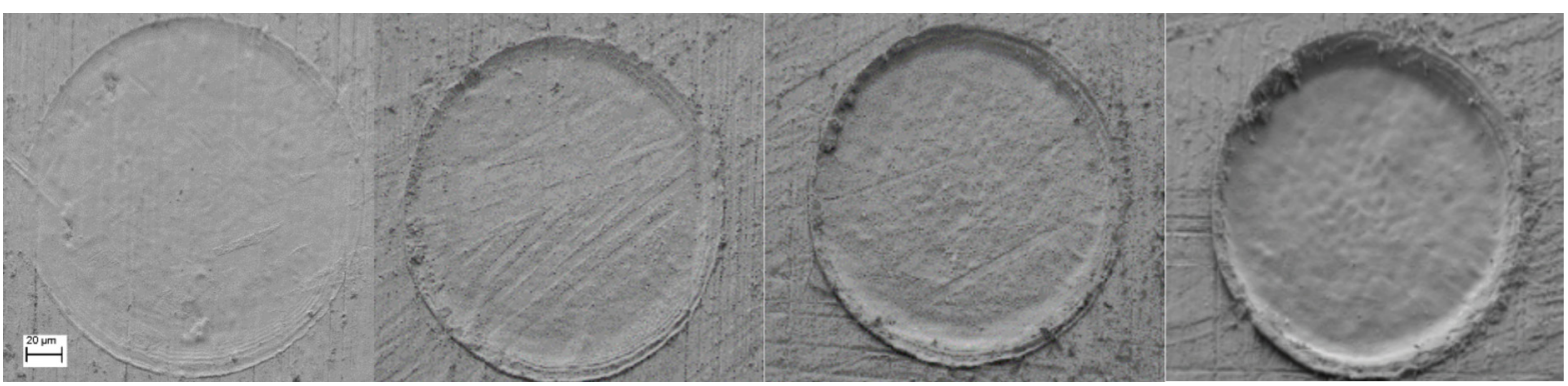

Fig. 3. Example SEM images after 1, 3, 6, 12 seconds of ablation ( $5 \mathrm{~Hz}, 160 \mu \mathrm{m}$ beam).

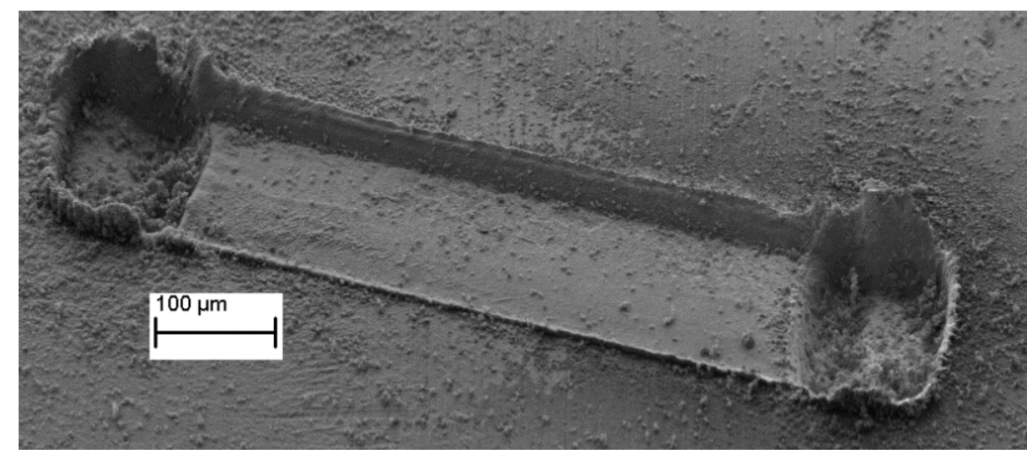

Fig. 4. Example SEM image of multiple ablation passes ( $5 \mathrm{~Hz}, 95 \mu \mathrm{m}$ square beam).

Calibration was performed by ablation on a set of inactive standards obtained via PSI (Paul Scherrer Institute, Switzerland). The standards consisted of pieces of cladding with an outer oxide, grown by autoclave exposure. The standards were implanted with ${ }^{7} \mathrm{Li}$ ions at ETH (Swiss Federal Institute of Technology), and were of the same kind as those used for ${ }^{7} \mathrm{Li}$ calibration of the SIMS equipment at PSI. SIMS measurements and SRIM calculations (Stopping and Range of Ions in Matter) of the implanted depth profile showed a peak ${ }^{7} \mathrm{Li}$ content $\sim 2.1 \mu \mathrm{m}$ inside the oxide. Reference [5] provides additional information on the SIMS analysis and on the use of the same type of implanted reference materials. With the above information and the implanted dose, the calculated peak ${ }^{7} \mathrm{Li}$ oxide content was used for calibration. The ablation depth rate was obtained by transforming the ablation time from the first rise in ${ }^{91} \mathrm{Zr}$ signal to the time to reach the ${ }^{7} \mathrm{Li}$ peak in the implanted standards, resulting in a depth rate of $0.5 \mu \mathrm{m} / \mathrm{s}$ (in good agreement with the SEM results). The same laser and ICP-MS settings were used for the standards and the samples within the analysis campaign. Figure 5 shows the $\mathrm{Zr}$-normalised ${ }^{7} \mathrm{Li}$ calibration plot.

The uncertainty of the ${ }^{7} \mathrm{Li}$ calibration is estimated at $\pm 10 \%$, or $\pm 0.5 \mathrm{ppm}$ for the lower concentrations.

As a secondary objective, non-matrix matched ${ }^{11} \mathrm{~B}$ intensity calibration was estimated from ablation on NIST 610 and 612 (National Institute of Standards and Technology, USA), standard reference material glasses, using the averaged $\mathrm{B}$ concentrations reported by Jochum et al. [6]. Non Zr-normalized ${ }^{11} \mathrm{~B}$ calibration was performed since the NIST glasses only contain minor amounts of Zr. The different matrixes, glass vs. $\mathrm{Zr} / \mathrm{ZrO}_{2}$ in the samples as well as variations in the ablated mass rate (geometry effects, sample density, etc.) could significantly affect the validity of the comparison.

The ${ }^{11} \mathrm{~B}$ calibration uncertainty is thus larger and is estimated at $\pm 100 \%$.

\section{$2.3^{7} \mathrm{Li}$ and ${ }^{11} \mathrm{~B}$ results}

Cladding analysis of the irradiated fuel rod was performed at a sample cut out in the lower area of the rod bow contact ( 1131 to $1141 \mathrm{~mm}$, marked by solid lines in Fig. 6), directly below the transversal metallography cross section at $1142 \mathrm{~mm}$ from the rod bottom end (marked by the dashed line in Fig. 6). The sample was transported to the laser ablation hot cell without any further preparation (no defueling required).

Figure 7 shows spot wise laser ablation performed at a rod elevation of ca. $1140 \mathrm{~mm}$ at four different rotations angles, using the same zero angle as in the original PIE work [1]. The $0^{\circ}{ }^{7} \mathrm{Li}$ depth profile shows the enormously elevated ${ }^{7} \mathrm{Li}$ content in the direction of the contact (near the area of maximum oxide thickness).

Figure 8 shows a contour plot with ${ }^{7} \mathrm{Li}$ results based on multiple line scans at an axial position of $\sim 1141 \mathrm{~mm}$ in the circumferential direction near $0^{\circ}$.

The line scans cover approximately $\pm 18^{\circ}$ of the circumference around the $0^{\circ}$ position. Each line pass corresponds to a step of $\sim 300 \mathrm{~nm}$ into the oxide from the oxide/coolant interface. Although it may appear that the outer surfaces are flat in the $\mathrm{Li}$ and B plots, it should be pointed out that this is an effect of defining the $x$-axis as the ablated depth from the outer oxide surface (from the rise in Zr-signal during ablation). In reality, both the outer and 


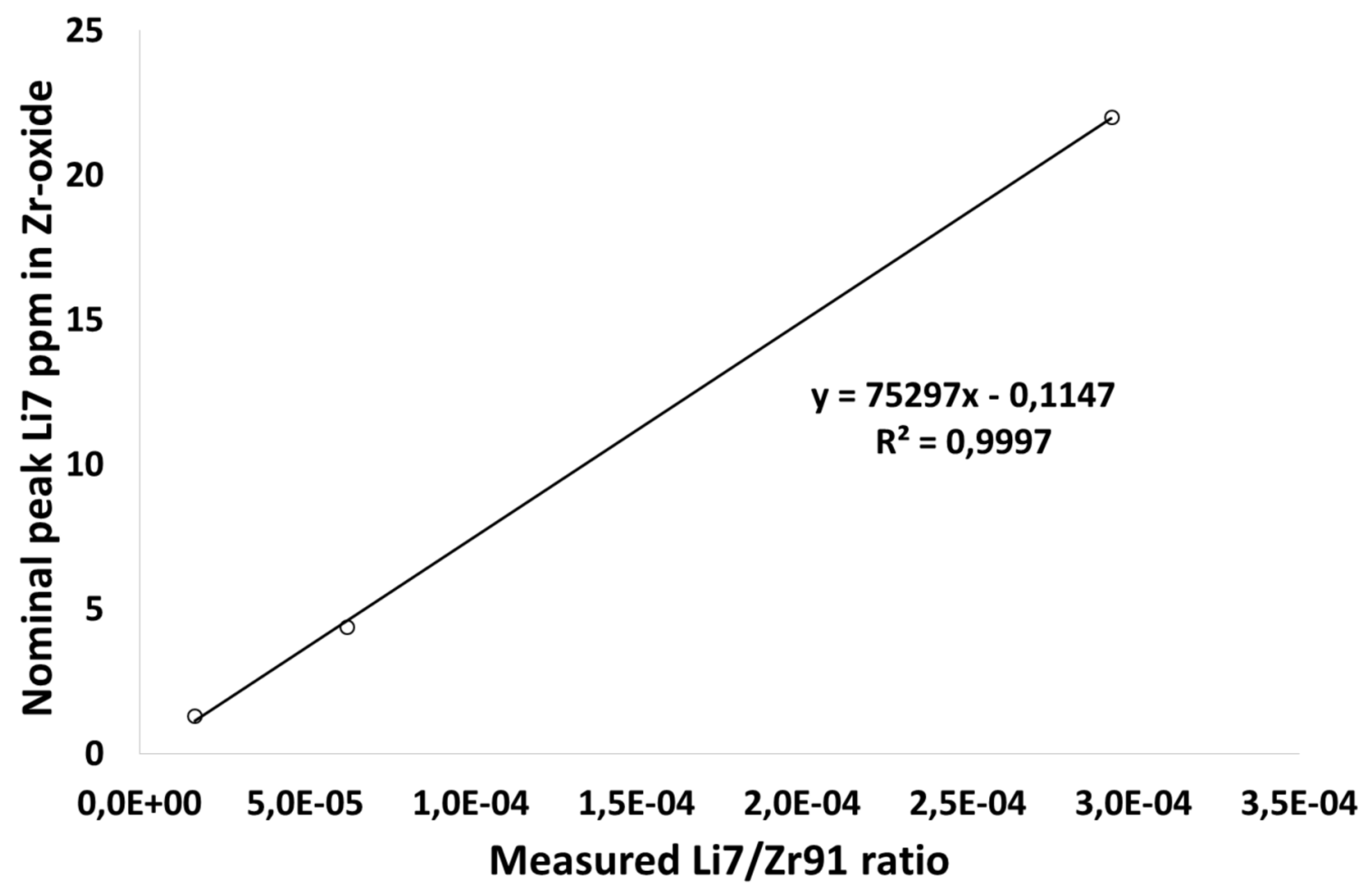

Fig. 5. ${ }^{7} \mathrm{Li}$ calibration curve from ablation on the inactive standards.

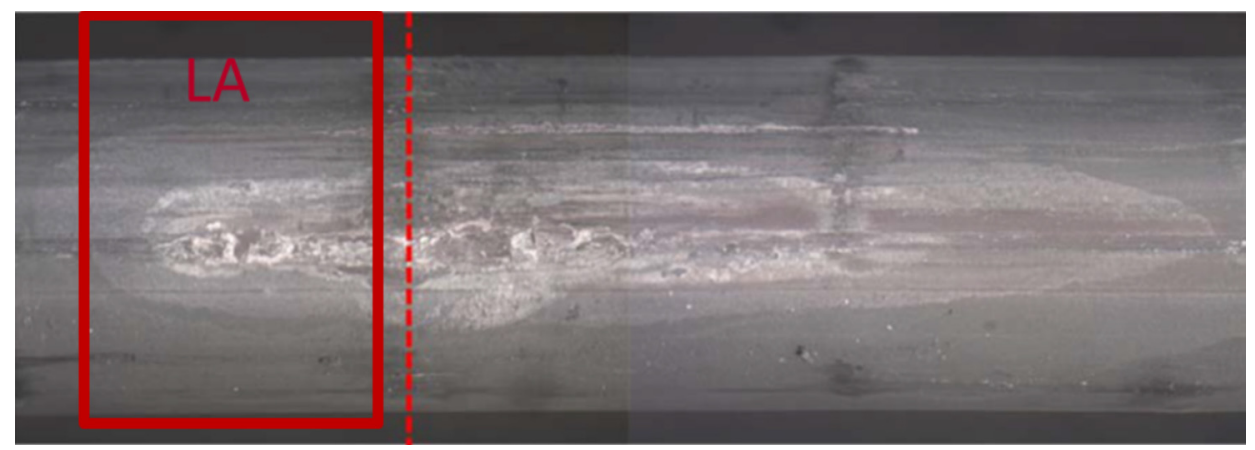

Fig. 6. Overview of the laser ablation sample relative to the contact area.

inner boundaries of the outer oxide (as well as the thickness) are actually quite irregular (Figs. 1 and 2). Since the sample is not rotated as the laser traverses the sample in the circumferential direction, there is also a small geometrical bias to overestimate the oxide thickness when the beam is the furthest from the normal plane $(\sim 0.5 \mu \mathrm{m}$ bias at the $\pm 18^{\circ}$ endpoints in Fig. 8).

Figure 9 shows a contour plot with ${ }^{11} \mathrm{~B}$ results based on multiple line scans at the axial position of $\sim 1141 \mathrm{~mm}$ in the circumferential direction near $0^{\circ}$ (same scan as the ${ }^{7} \mathrm{Li}$ results in Fig. 8).

Figure 10 shows a contour plot with ${ }^{7} \mathrm{Li}$ results from multiple line scans at the axial position of $\sim 1132 \mathrm{~mm}$ (a few millimetres below the contact) in the circumferential direction near $0^{\circ}$.

Figure 11 shows a contour plot with ${ }^{11} \mathrm{~B}$ results based on multiple line scans at the axial position of $\sim 1132 \mathrm{~mm}$ in the circumferential direction near $0^{\circ}$ (same scan as the ${ }^{7} \mathrm{Li}$ results in Fig. 10).
Figure 12 shows a contour plot with ${ }^{7}$ Li results based on multiple line scans at the axial position of $\sim 1140 \mathrm{~mm}$ in the circumferential direction near $180^{\circ}$.

Figure 13 shows a contour plot with ${ }^{11} \mathrm{~B}$ results based on multiple line scans at the axial position of $\sim 1140 \mathrm{~mm}$ in the circumferential direction near $180^{\circ}$ (same scan as in Fig. 12).

\section{Discussion \& summary}

The results show that the ${ }^{7} \mathrm{Li}$ content in the oxide with a normal thickness $(\sim 10 \mu \mathrm{m})$ are in agreement with previous results from irradiated $\mathrm{M} 5^{\mathrm{TM}}$ claddings [7], showing a maximum of $\sim 10$ to $20 \mathrm{ppm}{ }^{7} \mathrm{Li}$ about $\sim 1$ to $2 \mu \mathrm{m}$ inside the oxide. This ${ }^{7} \mathrm{Li}$ oxide distribution is illustrated in Figure 14 (left), which is an alternative plot showing the same data as in Figure 12.

Figure 14 (right), which is a ${ }^{7} \mathrm{Li}$ plot from the contact area with the maximum oxide thickness near $0^{\circ}$, illustrates the highly localised and strongly enhanced ${ }^{7} \mathrm{Li}$ content at that 


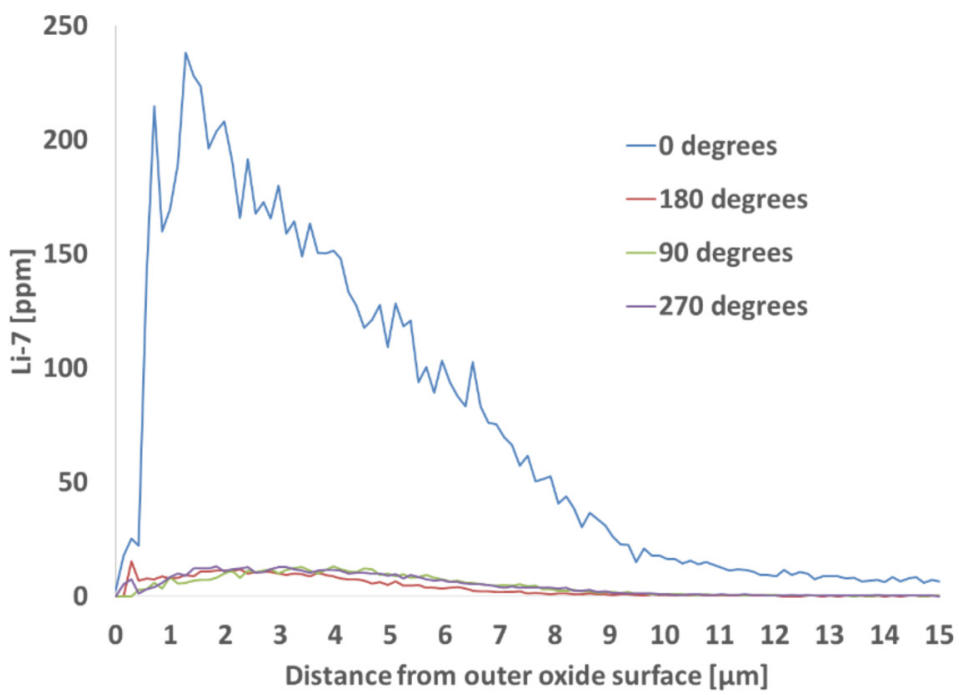

Fig. 7. ${ }^{7} \mathrm{Li}$ results at four circumferential angles with the rod contact at $\sim 0^{\circ}$.

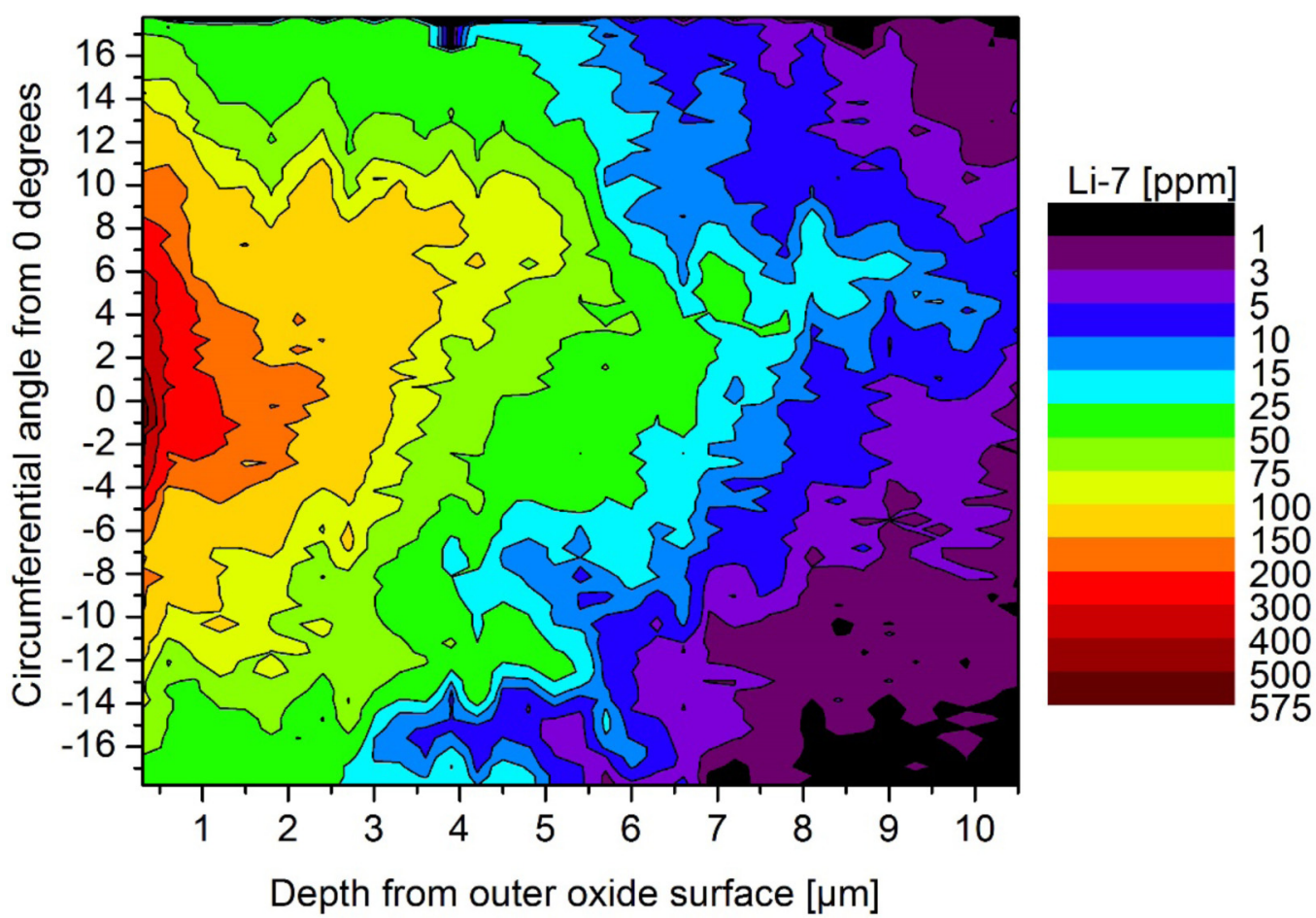

Fig. 8. ${ }^{7} \mathrm{Li}$ contour plot at $\sim 1141 \mathrm{~mm}$ with circumferential line scans near $0^{\circ}$ (oxide thickness $35-50 \mu \mathrm{m}$ ).

location. The circumferential ${ }^{7} \mathrm{Li}$ concentration profile appears to follow the oxide thickness profile with a maximum ${ }^{7} \mathrm{Li}$ concentration of almost $600 \mathrm{ppm}$ on the surface of the oxide close to the point of maximum oxide thickness $(\sim 50 \mu \mathrm{m})$. This peak $\mathrm{Li}$ value equates to $\sim 0.35$ atom $\% \mathrm{Li}$, if the bulk of the oxide is assumed to be $\mathrm{ZrO}_{2}$. One should point out that the axial elevation of the sample ( $1140 \mathrm{~mm}$ from the bottom end plug) is from a location with no or very limited conditions of local boiling during normal operating conditions.

The maximum ${ }^{7} \mathrm{Li}$ gradient inside the oxide, in the contact zone, is considerable, with ${ }^{7} \mathrm{Li}$ concentrations going from $>500 \mathrm{ppm}$ at the surface of the contact to $<10 \mathrm{ppm}$ approximately $10 \mu \mathrm{m}$ inside the oxide (local oxide thickness $30-50 \mu \mathrm{m})$. The enhanced Li content thus seems to be related to the outer surface of the oxide, and not to the deeper parts of the oxide or the clad-oxide interface. These results contrast with the flatter $\mathrm{Li}$ oxide depth profiles from experiments on $\mathrm{Li}$ enhanced rapid corrosion of Zry-4 at high local voids $[2,4]$. Keeping in mind that the cladding in this study is the $\mathrm{Nb}$ containing $\mathrm{M} 5^{\mathrm{TM}}$ alloy, the results do however have similarities with $\mathrm{Li}$ and $\mathrm{B}$ profiles from other $\mathrm{Li}$ and $\mathrm{B}$ corrosion tests [8]. Interestingly, [8] tentatively identifies a beneficial effect of a more compact (impermeable to $\mathrm{Li}$ ) oxide close to the metal interface of $\mathrm{Nb}$ containing Zr-alloys. A recent out-of-pile autoclave study points in the same direction [9]. 


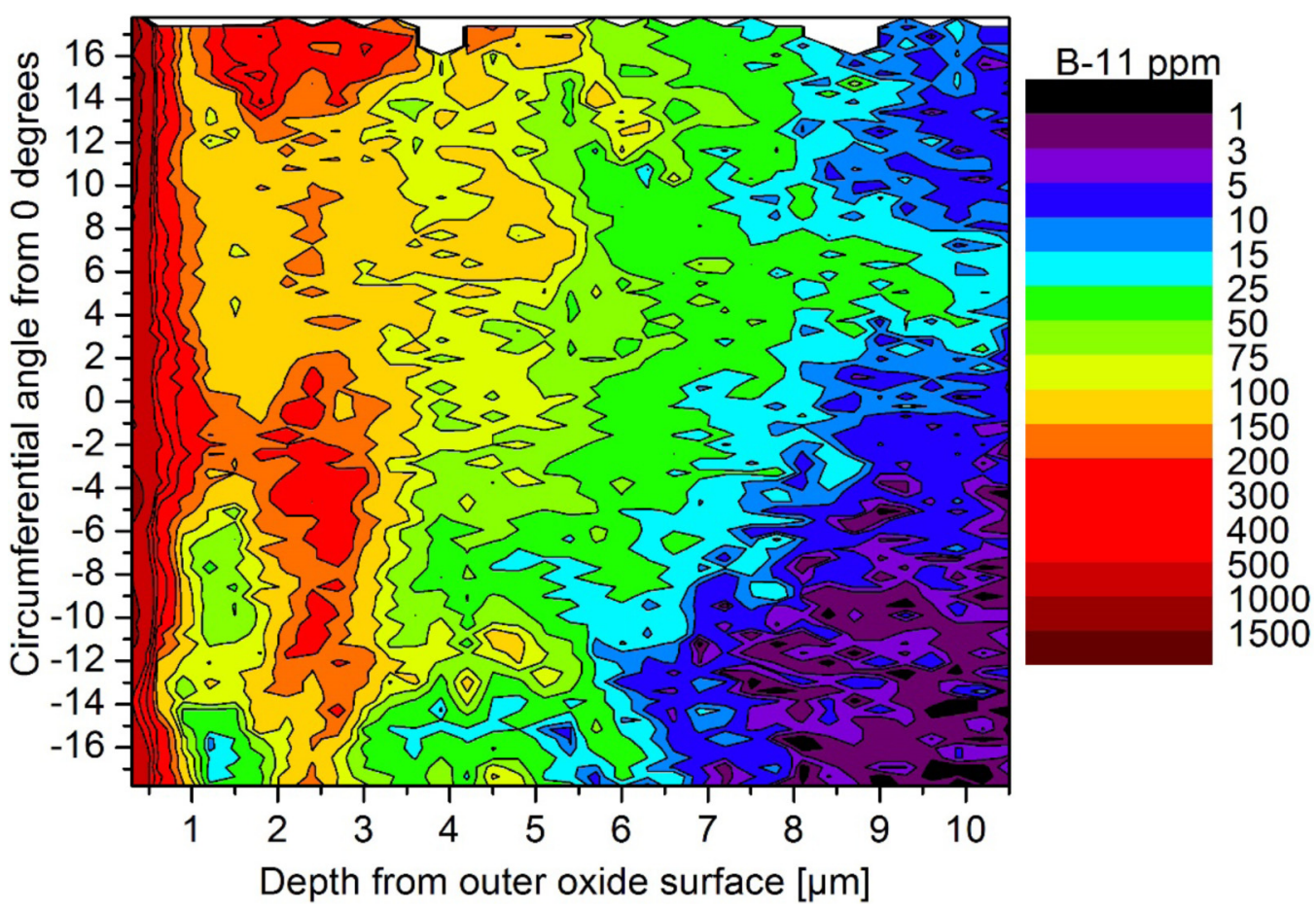

Fig. 9. ${ }^{11} \mathrm{~B}$ contour plot at $\sim 1141 \mathrm{~mm}$ with circumferential line scans near $0^{\circ}$ (oxide thickness $35-50 \mu \mathrm{m}$ ).

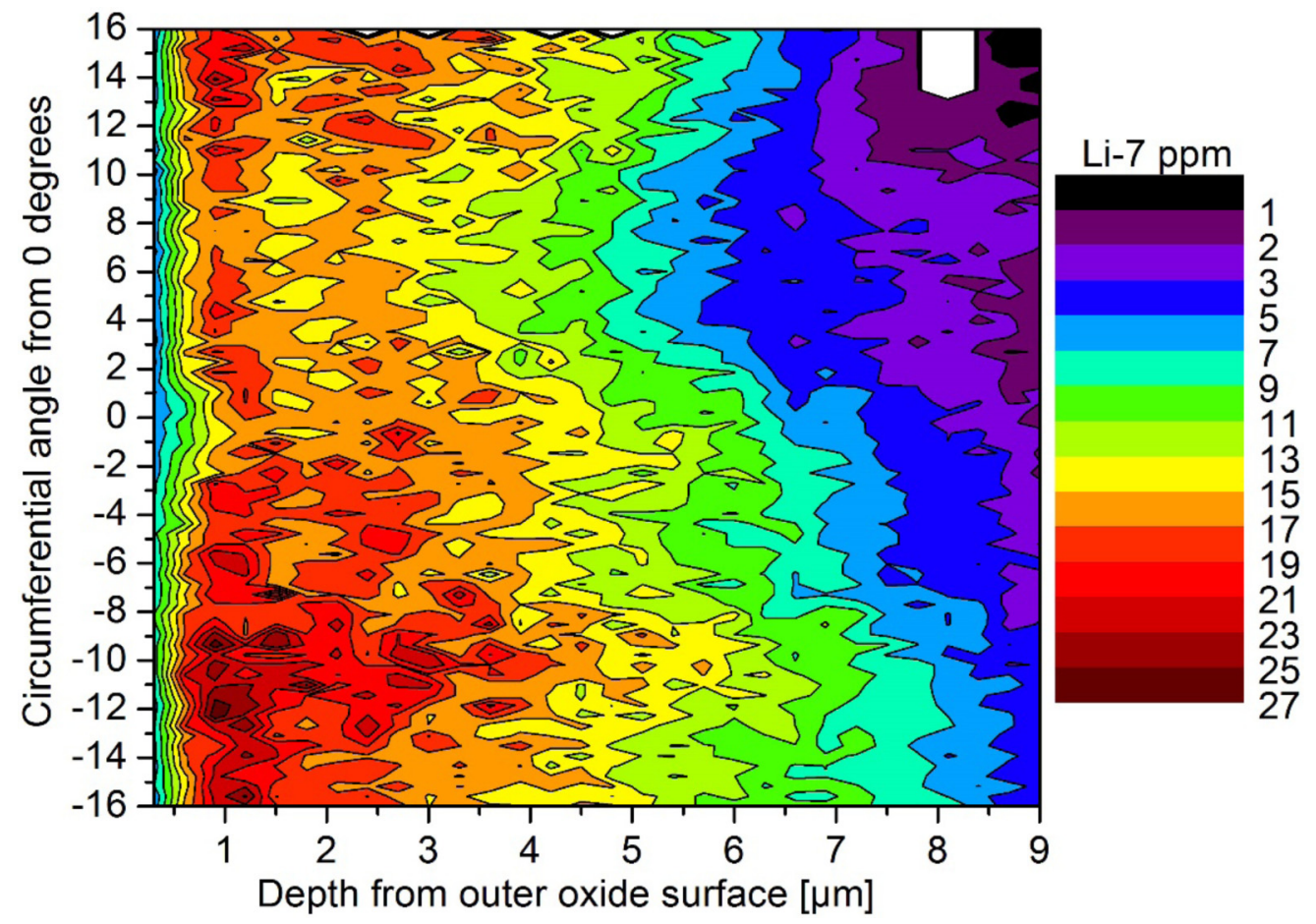

Fig. 10. ${ }^{7} \mathrm{Li}$ contour plot at $\sim 1132 \mathrm{~mm}$ with circumferential line scans near $0^{\circ}$ (oxide thickness $8-10 \mu \mathrm{m}$ ).

It should, however, be noted that potential hideout effects upon reactor shutdown and subsequent in pool storage might contribute to the observed results in this study. One should also keep in mind that a considerable amount of oxide probably spalled off in the contact region (based on reduced metal thickness and Pilling-Bedworth ratio). The Li and B contents of any spalled oxide remains unknown. It is, nevertheless, intriguing that the innermost oxide layer approaching the oxide/clad interface has a very low Li content in all sampled positions (Figs. 8, 10, 12 and 14), despite the strong evidence for local $\mathrm{Li}$ induced corrosion at the rod-to-rod contact area. 


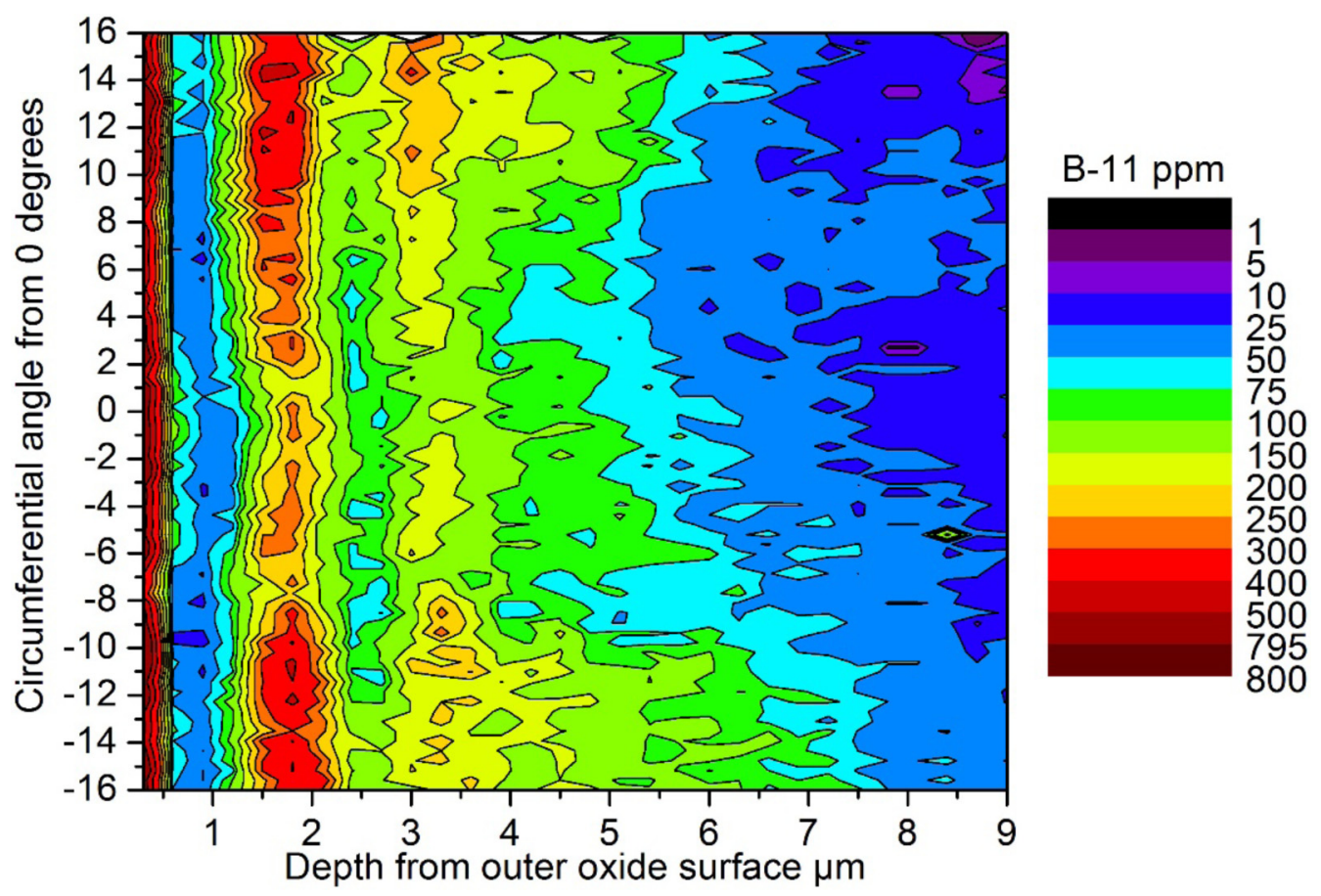

Fig. 11. ${ }^{11} \mathrm{~B}$ contour plot at $\sim 1132 \mathrm{~mm}$ with circumferential line scans near $0^{\circ}$ (oxide thickness $8-10 \mu \mathrm{m}$ ).

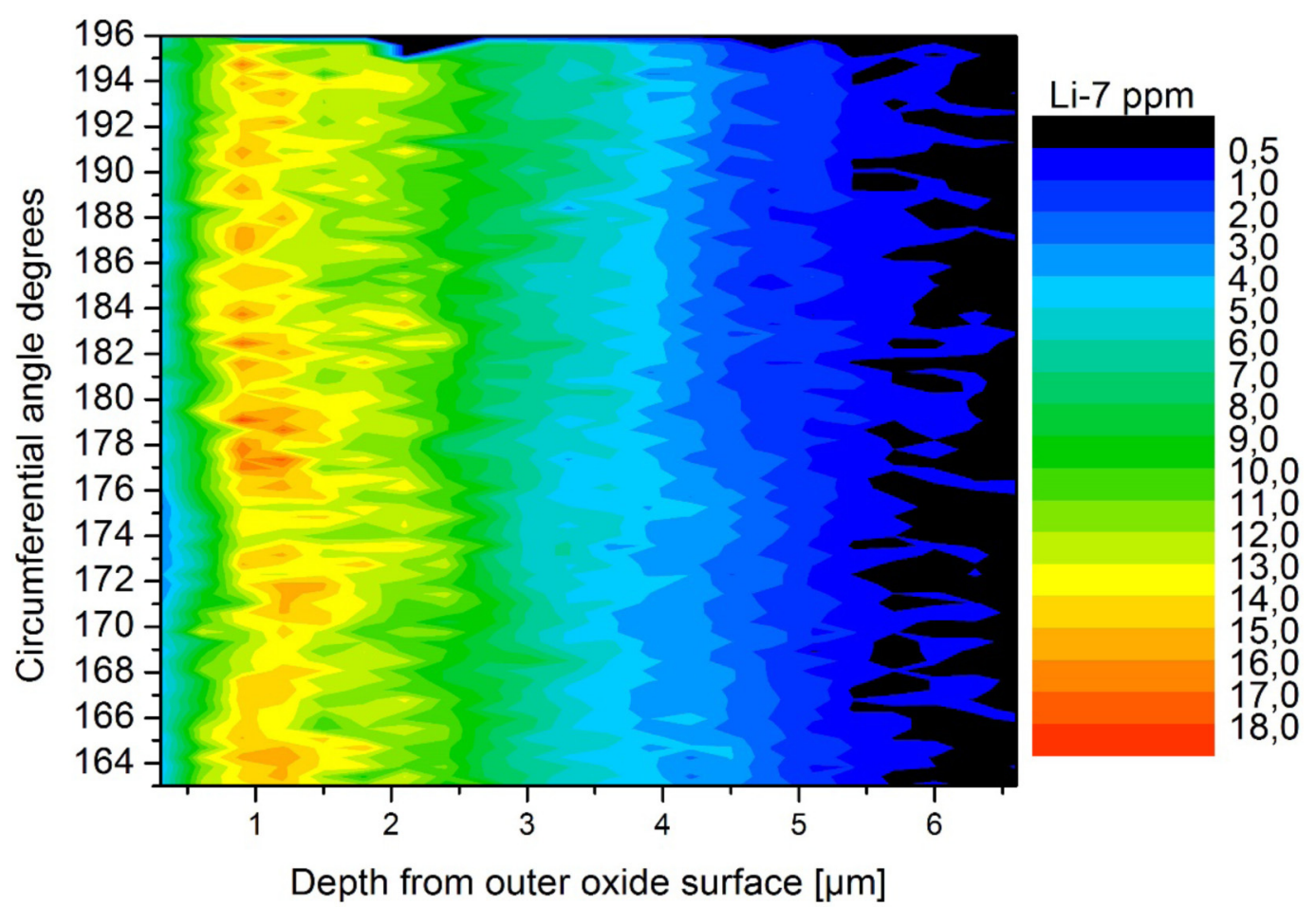

Fig. 12. ${ }^{7} \mathrm{Li}$ contour plot at $\sim 1140 \mathrm{~mm}$ with circumferential line scans near $180^{\circ}$ (oxide thickness $8-10 \mu \mathrm{m}$ ).

Analysis of the ${ }^{11} \mathrm{~B}$ content (Figs. 9, 11 and 13) was largely in agreement with previous investigations [7], although it should be noted that the ${ }^{11} \mathrm{~B}$ results are more uncertain, being a secondary objective of this study. At the location of the rod-to-rod contact, the ${ }^{11} \mathrm{~B}$ content could possibly be slightly enhanced, reaching $\sim 1500 \mathrm{ppm}$ in a very thin outer layer, in comparison with values of $\sim 500$ to $1000 \mathrm{ppm}$ at the outer surfaces of the other locations. The thin outermost ${ }^{11} \mathrm{~B}$ layer is probably due to drying in of spent fuel pool water $\left(2000+\right.$ ppm B, no added Li). The ${ }^{11} \mathrm{~B}$ profiles also typically displayed a second peak $\sim 2 \mu \mathrm{m}$ into the oxide, and sometimes a third more diffuse peak at $\sim 3$ to 


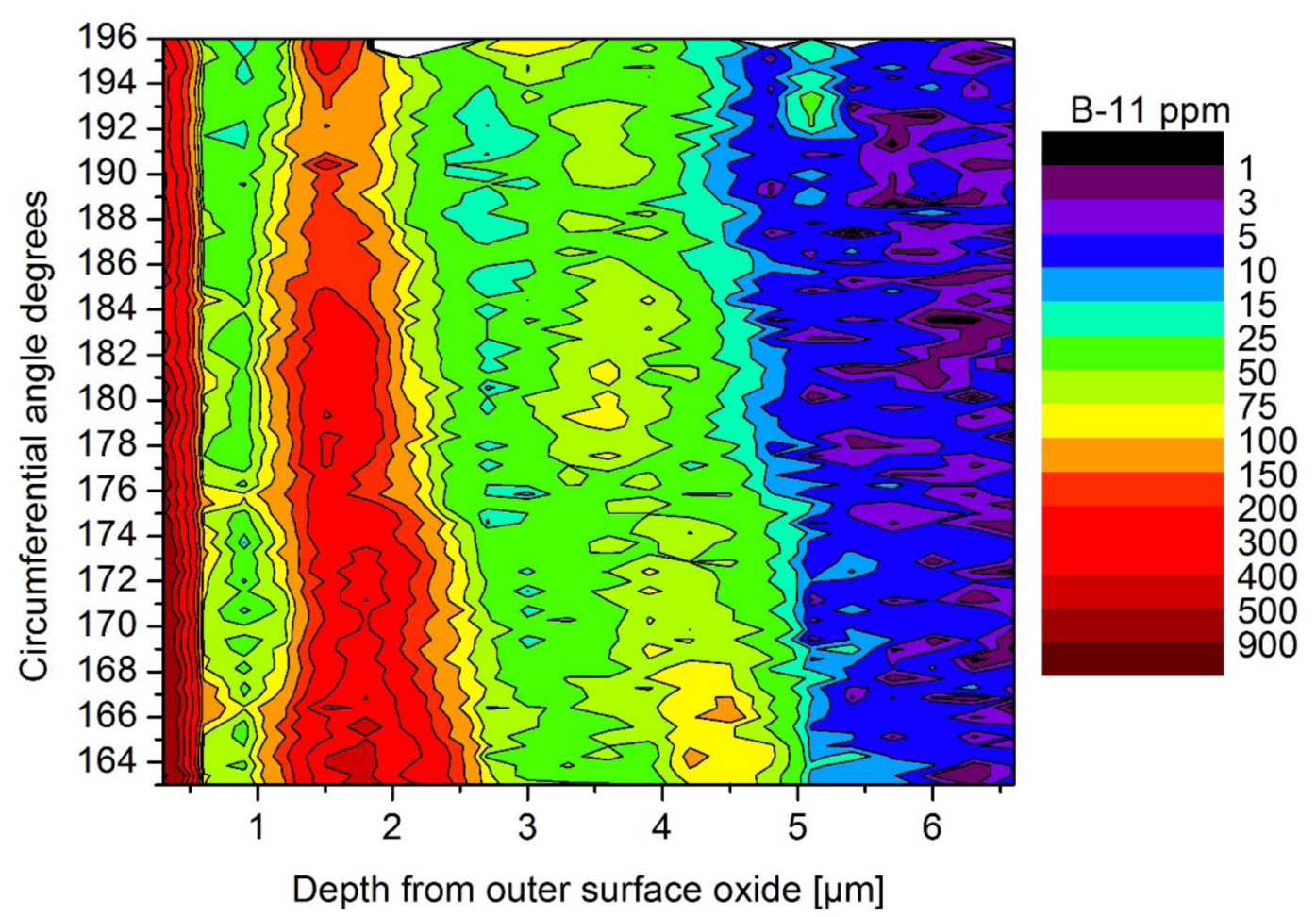

Fig. 13. ${ }^{11} \mathrm{~B}$ contour plot at $\sim 1140 \mathrm{~mm}$ with circumferential line scans near $180^{\circ}$ (oxide thickness $8-10 \mu \mathrm{m}$ ).
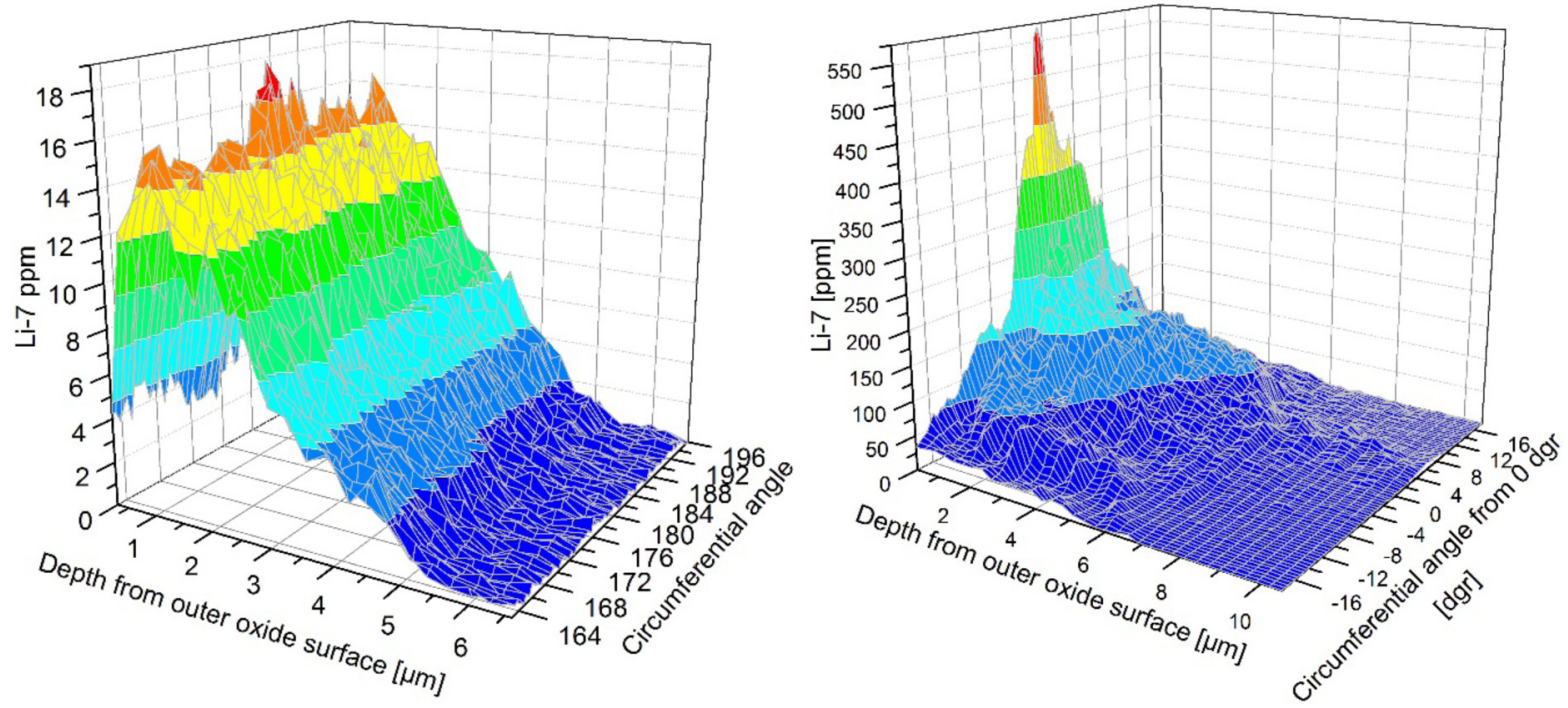

Fig. 14. ${ }^{7} \mathrm{Li}$ plot with same data as in Figures 12 (left) and 8 (right). The left plot shows the ${ }^{7}$ Li distribution in the oxide with normal thickness $(8-10 \mu \mathrm{m})$ at $180^{\circ}$. The right plot shows the strongly elevated ${ }^{7} \mathrm{Li}$ at the area of rod-to-rod contact $(\sim 35-50 \mu \mathrm{m}$ oxide thickness).

$4 \mu \mathrm{m}$ depth. These ${ }^{11} \mathrm{~B}$ peaks do not appear to be correlated with the layering of the oxide (Fig. 2). In the areas with normal oxide thickness away from the contact zone, the peak ${ }^{7} \mathrm{Li}$ and ${ }^{11} \mathrm{~B}$ concentrations appear to occur at different depths in the oxide.

In summary, the considerable and highly localised increase in $\mathrm{Li}$ content at the area of enhanced corrosion offers strong evidence for a case of $\mathrm{Li}$ induced breakaway corrosion during power operation. One could also argue that the exact Li bulk concentration in the reactor water ( \pm a few ppm Li) may probably be of minor importance, compared with the likely key factor, the local boiling introduced by the high enough heat flux and poor flow conditions around the rod-to-rod contact, causing a very local increase in Li concentration.

Vattenfall Nuclear Fuel AB is acknowledged for commissioning of the work. 


\section{References}

1. D.I. Schrire et al., Post-irradiation examination of a bowed PWR fuel rod with contact, in Proceedings of WRFPM 2014, Sendai, Japan, September 14-17, 2014 (2014), Paper 100155

2. P. Billot et al., Experimental and theoretical studies of parameters that influence corrosion of Zircaloy-4, in 10th ASTM Symposium on zirconium in the Nuclear Industry, ASTM STP 1245, Philadelphia, USA (1994), p. 351

3. B. Cox et al., Waterside corrosion of zirconium alloys in nuclear power plants, IAEA TECDOC 996, 124 (1998)

4. P. Billot et al., The role of lithium and boron on the corrosion of Zircaloy-4 under demanding PWR-type conditions, in 13th $A S T M$ symposium on Zirconium in the nuclear industry, $A S T M S T P 1423$ (2002), p. 169
5. D. Gavillet et al., Comparison of two analytical methods for the local quantitative determination of lithium and boron contents in cladding materials, in Proceedings of Atalante, 2008 Montpellier, France, May 19-22, 2008 (2008), Paper O5_05

6. K. Jochum et al., Geostand. Geoanal. Res. 35, 397 (2011)

7. P. Bossis et al., Corrosion of M5 in PWRs: quantification of $\mathrm{Li}, \mathrm{B}, \mathrm{H}$ and $\mathrm{Nb}$ in the oxide layers formed under different conditions, in Zirconium in the nuclear industry: 16th international symposium, Chengdu, China, May 10-13, 2010 (2010)

8. O. Gebhardt, D. Gavillet, SIMS depth profiling analyses on in-reactor corroded Zircaloy cladding species, in IAEATECDOC-1128 (1999), p. 151

9. S. Muller, L. Lanzani, Corrosion of zirconium alloys in concentrated lithium hydroxide solutions, J. Nucl. Mater. 439, 251 (2013)

Cite this article as: Anders Puranen, Pia Tejland, Michael Granfors, David Schrire, Bertil Josefsson, Bernt Bengtsson, Lithium and boron analysis by LA-ICP-MS results from a bowed PWR rod with contact, EPJ Nuclear Sci. Technol. 3, 2 (2017) 